\title{
Novel Genes of Fusarium graminearum That Negatively Regulate Deoxynivalenol Production and Virulence
}

\author{
Donald M. Gardiner, Kemal Kazan, and John M. Manners \\ CSIRO Plant Industry, Queensland Bioscience Precinct, 306 Carmody Road, St. Lucia, Queensland 4067, Australia
}

Submitted 6 May 2009. Accepted 20 July 2009.

\begin{abstract}
Fusarium head blight of wheat, caused by Fusarium graminearum, is a serious disease resulting in both reduced yields and contamination of grain with trichothecene toxins, with severe consequences for mammalian health. Recently, we have identified several related amine compounds such as agmatine and putrescine that promote the production of high levels of trichothecene toxins, such as deoxynivalenol (DON), in culture by $F$. graminearum and $F$. sporotrichioides. Here, a global analysis of fungal gene expression using the Affymetrix Fusarium GeneChip during culture under DON-inducing conditions compared with noninducing conditions is reported. Agmatine differentially regulated a large number of fungal genes, including both known and previously uncharacterized putative secondary metabolite biosynthetic gene clusters. In silico prediction of binding sites for the transcriptional regulator (TRI6) controlling TRI gene expression and gene expression analysis in a TRI6 mutant of $F$. graminearum showed that three of the differentially regulated genes were under the control of TRI6. Gene knock-out mutations of two of these genes resulted in mutants with massively increased production of DON and increased aggressiveness toward wheat. Our results not only identify a novel mechanism of negative regulation of DON production and virulence in $F$. graminearum but also point out the potential of this pathogen to evolve with an ability to produce massively increased amounts of toxins and increased virulence.
\end{abstract}

Fusarium head blight (FHB) of wheat, caused by Fusarium graminearum and related Fusarium spp., is one of the most important fungal diseases of wheat worldwide. Under the appropriate weather conditions, the pathogen infects the spikelets at the time of anthesis and ensuing disease can devastate developing heads (Goswami and Kistler 2004). In addition to substantial yield losses due to a combination of floret sterility and shrunken and discolored grains, the trichothecene mycotoxins, such as deoxynivalenol (DON), produced by the fungus accumulate in infected grain. These toxins have severe health consequences for humans and animals that consume products made from contaminated grain. Therefore, a better understanding of environmental and genetic factors regulating toxin biosynthesis can lead to the development of new strategies aimed at reducing toxin accumulation in the host tissue.

Corresponding author: Donald Gardiner; Telephone: +61 (0)7 3214 2370; Fax: +61 (0)7 3214 2920; E-mail: donald.gardiner@csiro.au

*The $\boldsymbol{e}$-Xtra logo stands for "electronic extra" and indicates that five supplementary figures and one supplementary table are published online.
Trichothecene biosynthesis from farnesyl pyrophosphate involves at least 15 different biochemical steps in Fusarium spp. (Desjardins 2006) and is regulated by a number of what are thought to be pathway-specific regulators such as TRI6, TRI10, TRI15, and possibly TRI14 (Proctor et al. 1995b; Tag et al. 2001; Alexander et al. 2004; Dyer et al. 2005). The first committed step in the pathway is conserved in all trichothecene-producing Fusarium spp. and catalyzed by the sesquiterpene synthase (trichodiene synthase) encoded by TRI5 (Hohn and Beremand 1989). Later steps in the pathway differ between different Fusarium spp. or isolates, leading to the biosynthesis of the variant trichothecenes (e.g., nivalenol and T-2 toxin) that are produced with differing patterns of oxygenation and esterification. These variations can be accounted for by underlying genetic differences. In the $F$. graminearum genome, the genes encoding enzymes and pathway-specific regulatory factors for the biosynthesis of DON are present at four loci (Hohn et al. 1993; Kimura et al. 1998; Meek et al. 2003; Alexander et al. 2004). All but one oxygenation step (the conversion of the C8 hydroxyl to a carbonyl group) and the deacetylation of $\mathrm{C} 15$ have been assigned an enzyme (McCormick et al. 2004). Also, a locus (TOX1) responsible for determining the amount of trichothecene toxin accumulated has been identified (Cumagun et al. 2004) but the corresponding gene is yet to be cloned. It has been suggested, based on alignment between genetic and physical maps and phenotypic similarities, that TOX1 may be the MGV1 gene encoding a mitogen-activated protein kinase essential for pathogenesis (Cumagun et al. 2004; Lee et al. 2008).

Fungal genomes, through the presence of genes encoding enzyme systems such as terpene synthases, polyketide synthases (PKS), and nonribosomal peptide synthetases (NPS), have the capacity to produce a large number of different secondary metabolites. However, in most cases, the actual number of metabolites known to be produced by a particular species is far fewer than those potentially encoded on the genome. For example, despite the presence of 15 PKS- and 19 NPS-like genes in $F$. graminearum, the products of only 5 and 3 such genes respectively, have so far been identified (Gaffoor et al. 2005; Tobiasen et al. 2007). The limited knowledge of the function of the remaining genes is most likely due to their expression only under very specific circumstances. For instance, $F$. graminearum genes (e.g., TRI5) involved in the production of the DON class of mycotoxins are only significantly expressed either in planta or under very specific in vitro conditions (Gardiner et al. 2009a and b).

In an effort to identify potential regulators of DON biosynthesis, we have recently discovered particular amine compounds (e.g., ornithine, agmatine, and putrescine) that could support, in defined media, levels of DON production and TRI5 expression equivalent to those observed during infection (Gardiner et 
al. 2009a). We were interested in whether other genes (particularly secondary metabolite gene clusters) were co-regulated by these compounds. Here, the effect of agmatine on $F$. graminearum global gene expression profiles is analyzed using the Fusarium GeneChip from Affymetrix (Güldener et al. 2006b). This analysis has led to the identification of previously functionally uncharacterized genes that were co-regulated with the TRI genes responsible for trichothecene production. Importantly, through functional analyses, we found that these uncharacterized agmatine-responsive genes also negatively regulate DON biosynthesis and virulence in $F$. graminearum.

\section{RESULTS}

\section{Gene expression profiling of $\boldsymbol{F}$. graminearum} in DON-inducing growth conditions.

We previously reported the induction of DON biosynthesis in $F$. graminearum by amines such as agmatine and putrescine (Gardiner et al. 2009a). Growth in agmatine as the sole nitrogen source resulted in the highest levels of DON production, with expression of the TRI5 gene peaking 4 days after the start of culture. In this study, we further investigated the potential effects of agmatine relative to the effect of glutamine, which does not induce TRI gene expression, on the global gene expression profiles of $F$. graminearum. RNA was isolated from the cultures of $F$. graminearum grown for 4 days in the presence of either agmatine or glutamine as a sole nitrogen source. A microarray experiment was then performed using the Affymetrix $F$. graminearum GeneChip, which includes almost every gene in the $F$. graminearum genome (Güldener et al. 2006b). The culture filtrates of agmatine-grown samples used for micro- array analysis contained $782 \pm 85 \mathrm{ppm}$ (standard error of the mean, $n=4$ ) DON, whereas DON was undetectable in culture filtrates where glutamine was supplied as a sole nitrogen source (enzyme-linked immunosorbent assay [ELISA] minimum detection limit $=0.5 \mathrm{ppm}$ ).

The microarray analyses revealed that the $F$. graminearum transcriptome differed greatly following growth in agmatine and glutamine. In total, 7,166 probe sets representing 6,356 genes in the FG3 annotation of the $F$. graminearum genome were statistically significantly $(P<0.01)$ differentially expressed between the two treatments. To further increase the stringency of analyses used to detect these genes, an arbitrary 10-fold cutoff value was applied. This resulted in identification of 130 and 181 genes that showed greater than 10-fold higher expression in agmatine (compared with glutamine) or glutamine (compared with agmatine), respectively. Analysis of the set of genes showing higher expression in agmatine using the $\mathrm{Mu}-$ nich Information Centre for Protein Sequences (MIPS) FunCat functional classification and annotation system (Ruepp et al. 2004) showed that the genes in the categories of "metabolism" $\left(P=2.3 \times 10^{-8}\right)$; "cellular transport, transport facilities, and transport routes" $\left(P 2.7 \times 10^{-4}\right)$; and "cell rescue, defense, and virulence" $\left(P 2.5 \times 10^{-5}\right)$ were significantly over-represented in this data set compared with their representation in the $F$. graminearum genome. The metabolism class was dominated by the subclasses of "amino acid" and also "secondary metabolism". In contrast, no major functional categories were statistically over- or under-represented compared with the genome as a whole for the genes showing higher expression in glutamine. The full output of FunCat distribution is given in Supplementary Table 1 .

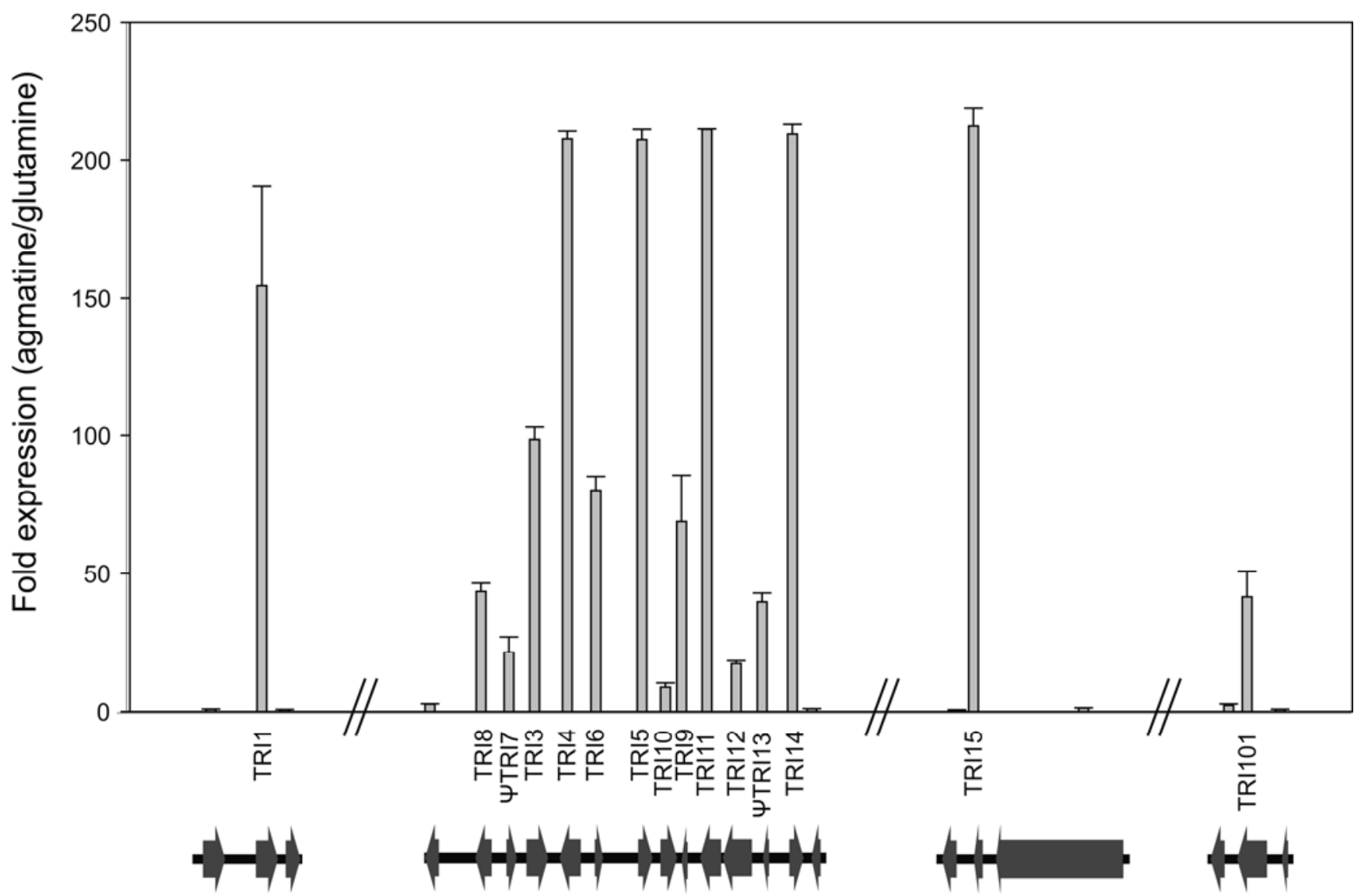

Fig. 1. Expression of TRI and immediate flanking genes in agmatine compared with glutamine as sole nitrogen sources, 4 days postinoculation. Gene expression was measured using the Fusarium graminearum Affymetrix Genechips. Error bars represent the standard error of the mean. All TRI genes show statistically significant upregulation in agmatine $(P<0.001)$. 
Agmatine is a strong inducer of all known TRI genes in F. graminearum.

Consistent with previous results (Gardiner et al. 2009a) and the detection of DON only in the agmatine-supplied media, a significantly higher $(P<0.001)$ expression of all known TRI genes, located at four separate loci in the $F$. graminearum genome, involved in biosynthesis or regulation of trichothecene production in Fusarium spp. was observed. TRI1, TRI3, TRI4, TRI5, TRI11, TRI14, and TRII5 all showed greater than 100-fold upregulation by agmatine compared with glutamine whereas TRIIO showed relatively modest induction $(8.7 \pm 1.5$-fold $)$ (Fig. 1). Affymetrix gene expression data were validated for a number of different genes using real-time quantitative reverse- transcriptase polymerase chain reaction (qRT-PCR) (Supplementary Fig. 1). Gene expression measured using qRT-PCR was consistent with the Affymetrix gene expression data. Interestingly, although the $F$. graminearum isolate used (CS3005) does not produce nivalenol (NIV) (data not shown), biosynthesis of which would require functional TRI7 and TRI13 genes (Lee et al. 2002), strong upregulation by agmatine was also observed for the presumed pseudogenes $\psi T R I 7$ and $\psi T R I 13$.

\section{New TRI6-regulated genes identified}

in the agmatine-induced gene set.

Based on the high levels of expression of nearly all known $T R I$ genes in the agmatine media, we hypothesized that other

Table 1. Fusarium graminearum genes showing at least 10-fold greater expression in agmatine than in glutamine and high correlation $(r>0.8)$ of their expression with TRI5 expression in planta

\begin{tabular}{|c|c|c|c|c|c|c|c|}
\hline Gene no. & $\begin{array}{l}\text { Gene } \\
\text { name }\end{array}$ & Description & $\begin{array}{l}\text { Correlation } \\
\text { with } \operatorname{TRI5}^{\mathrm{a}}\end{array}$ & $\begin{array}{l}\text { In planta } \\
\text { only }^{b}\end{array}$ & $\begin{array}{c}\text { Fold- } \\
\text { induction } \\
\text { by } \\
\text { agmatine }\end{array}$ & $\begin{array}{c}\text { No. of } \\
\text { predicted } \\
\text { TRI6 } \\
\text { binding site }\end{array}$ & $P$ values \\
\hline FGSG_00007 & & $\begin{array}{l}\text { Related to } O \text {-methylsterigmatocystin oxidoreductase } \\
\quad \text { (cytochrome } \mathrm{P} 450 \text { monooxygenase) }\end{array}$ & 0.97 & Yes & 148.9 & 1 & $5.9 \mathrm{e}^{-5}$ \\
\hline FGSG_00071 & $T R I 1$ & Cytochrome P450 monooxygenase & 0.99 & $\ldots$ & 140.9 & 1 & $1.1 \mathrm{e}^{-5}$ \\
\hline FGSG_01819 & & Conserved hypothetical protein & 0.95 & Yes & 17.8 & 0 & $\ldots$ \\
\hline FGSG_01832 & & Conserved hypothetical protein & 0.87 & $\ldots$ & 18.5 & 0 & $\ldots$ \\
\hline FGSG_02273 & & Probable aldehyde dehydrogenase & 0.88 & $\ldots$ & 10.5 & 0 & $\ldots$ \\
\hline FGSG_02852 & & Probable maleylacetoacetate isomerase & 0.99 & $\ldots$ & 17.4 & 0 & $\ldots$ \\
\hline FGSG_03008 & & $\begin{array}{l}\text { Related to pisatin demethylase/cytochrome P450 } \\
\text { monooxygenase }\end{array}$ & 0.94 & $\cdots$ & 15.2 & 0 & \\
\hline FGSG_03123 & & Conserved hypothetical protein & 0.87 & $\cdots$ & 15.5 & 1 & $8.2 \mathrm{e}^{-5}$ \\
\hline FGSG_03175 & & Related to quinone reductase & 0.83 & Yes & 16.6 & 0 & $\ldots$ \\
\hline FGSG_03532 & TRI8 & Trichothecene 3-O-esterase & 1.00 & $\cdots$ & 43.7 & 3 & $\begin{array}{l}1.1 \mathrm{e}^{-5} \\
4.5 \mathrm{e}^{-5} \\
4.5 \mathrm{e}^{-5}\end{array}$ \\
\hline FGSG_03534 & TRI3 & Trichothecene $15-O$-acetyltransferase & 1.00 & Yes & 98.5 & 0 & $\ldots$ \\
\hline FGSG_03535 & TRI4 & Trichodiene oxygenase (cytochrome P450) & 0.99 & & 207.7 & 1 & $1.1 \mathrm{e}^{-5}$ \\
\hline FGSG_03536 & TRI6 & Trichothecene biosynthesis positive transcription factor & 0.97 & Yes & 80.3 & 1 & $1.1 \mathrm{e}^{-5}$ \\
\hline FGSG_03537 & TRI5 & Trichodiene synthase (sesquiterpene cyclase) & 1.00 & Yes & 207.3 & 3 & $\begin{array}{l}5.9 \mathrm{e}^{-5} \\
2.5 \mathrm{e}^{-5} \\
2.5 \mathrm{e}^{-5}\end{array}$ \\
\hline FGSG_03539 & TRI9 & Putative trichothecene biosynthesis gene & 1.00 & $\cdots$ & 70.2 & 4 & $\begin{array}{l}1.1 \mathrm{e}^{-5}, \\
9.1 \mathrm{e}^{-5}, \\
1.1 \mathrm{e}^{-5}, \\
1.1 \mathrm{e}^{-5}\end{array}$ \\
\hline FGSG_03540 & TRI11 & Isotrichodermin C-15 hydroxylase & 0.99 & Yes & 203.6 & 2 & $\begin{array}{l}4.5 \mathrm{e}^{-5} \\
2.5 \mathrm{e}^{-5}\end{array}$ \\
\hline FGSG_03541 & TRI12 & Trichothecene efflux pump & 0.99 & $\ldots$ & 17.3 & 1 & $1.1 \mathrm{e}^{-5}$ \\
\hline FGSG_03543 & $T R I 14$ & Putative trichothecene biosynthesis gene & 1.00 & Yes & 209.4 & 2 & $\begin{array}{l}8.2 \mathrm{e}^{-5} \\
1.1 \mathrm{e}^{-5}\end{array}$ \\
\hline FGSG_03662 & & Conserved hypothetical protein & 0.94 & $\ldots$ & 13.9 & 0 & $\ldots$ \\
\hline FGSG_03700 & & Related to $O$-methylsterigmatocystin oxidoreductase & 0.90 & $\ldots$ & 13.3 & 0 & $\ldots$ \\
\hline FGSG_03933 & & Conserved hypothetical protein & 0.81 & $\ldots$ & 13.1 & 0 & $\ldots$ \\
\hline FGSG_04196 & & Probable UGA2 - succinate semialdehyde dehydrogenase & 0.82 & $\ldots$ & 11.3 & 0 & $\ldots$ \\
\hline FGSG_04575 & & Conserved hypothetical protein & 0.99 & $\ldots$ & 10.9 & 1 & $2.5 \mathrm{e}^{-5}$ \\
\hline FGSG_04735 & & Conserved hypothetical protein & 0.84 & $\ldots$ & 11.9 & 0 & $\ldots$ \\
\hline FGSG_04741 & & Conserved hypothetical protein & 0.92 & Yes & 20.1 & 0 & $\ldots$ \\
\hline FGSG_06000 & & Conserved hypothetical protein & 0.92 & $\ldots$ & 10.5 & 0 & $\ldots$ \\
\hline FGSG_07562 & & Related to hydroxylase & 0.91 & Yes & 10.1 & 1 & $2.5 \mathrm{e}^{-5}$ \\
\hline FGSG_07807 & & Conserved hypothetical protein & 0.84 & Yes & 28.2 & 0 & $\ldots$ \\
\hline FGSG_07830 & & Putative protein [EST hit] & 0.88 & $\ldots$ & 14.3 & 0 & $\ldots$ \\
\hline FGSG_07896 & TRI101 & Trichothecene $3-O$-acetyltransferase & 1.00 & $\ldots$ & 44.1 & 1 & $2.5 \mathrm{e}^{-5}$ \\
\hline FGSG_08077 & & Related to flavin oxidoreductase & 0.97 & $\ldots$ & 28.0 & 0 & $\ldots$ \\
\hline FGSG_08078 & & Related to general amidase & 0.99 & $\ldots$ & 20.2 & 0 & $\ldots$ \\
\hline FGSG_10397 & & Conserved hypothetical protein & 0.96 & Yes & 177.1 & 3 & $\begin{array}{l}2.5 \mathrm{e}^{-5} \\
4.5 \mathrm{e}^{-5} \\
1.1 \mathrm{e}^{-5}\end{array}$ \\
\hline FGSG_12292 & & Conserved hypothetical protein & 0.92 & $\ldots$ & 14.2 & 0 & $\ldots$ \\
\hline FGSG_12555 & & Putative protein (expressed sequence tag hit) & 0.80 & $\ldots$ & 14.6 & 0 & $\ldots$ \\
\hline FGSG_13521 & & Putative protein (expressed sequence tag hit) & 0.80 & $\ldots$ & 10.9 & 0 & $\ldots$ \\
\hline
\end{tabular}

${ }^{a}$ Pearson correlation coefficient with TRI5 during Fusarium head blight of barley (Güldener et al. 2006b).

${ }^{\mathrm{b}}$ Defined as "in planta only" by Güldener and associates (2006b).

${ }^{c}$ The $P$ value is the probability of finding such a match in the sequence. Matches to the motifs TCAGGCCT and TTAGGCCT, i.e., the best matches to the TRIG binding site, have $P$ values of $1.1 \mathrm{e}^{-5}$ and $2.5 \mathrm{e}^{-5}$, respectively 
genes highly expressed under these conditions might also be involved in either the regulation or biosynthesis of trichothecene toxins. To identify a subset of candidate genes that may also show increased in planta expression and, hence, have possible roles in infection-related processes, the 130 genes showing higher expression in agmatine were analyzed for their TRI5like expression profiles in the barley- $F$. graminearum infection time-course of Güldener and associates (2006b). In total, 36 genes, including 13 known TRI genes, had Pearson correlation coefficients of greater than 0.8 with the TRI5 profile (Table 1). Because the TRI6 zinc finger transcription factor is known to regulate the expression of TRI genes involved in DON biosynthesis, these new genes might also be regulated by TRI6. Therefore, the promoter regions of these genes were searched for the presence of putative TRI6 binding sites using the Motif Alignment and Search Tool (MAST) program (Bailey and Gribskov 1998). The search identified five non-TRI genes (FGSG_00007, FGSG_10397, FGSG_04575, FGSG_07562, and FGSG_03123) with putative TRI6 binding sites in their promoters. These are shown in Table 1 with their fold-expression and correlation with TRI5 gene expression during FHB of barley.

To test the potential regulation of these selected genes by TRI6, the expression from these genes was measured in a TRI6 mutant (in a CS3005 wild-type background) and compared with that of the expression in the wild-type fungus (Fig. 2). Similar to TRI5, TRII, and TRI101, which are known to be positively regulated by TRI6 (Proctor et al. 1995b; Peplow et al. 2003), FGSG_00007 $(P<0.013)$ and $F G S G \_10397(P<$ $0.005)$ showed downregulation in the TRI6 mutant, suggesting that TRI6 also positively regulates these genes. No change in expression from FGSG_04575 and FGSG_07562 was found (Fig. 2); therefore, these two genes did not appear to be under the control of TRI6. In contrast, FGSG_03123 appeared to be negatively regulated by TRI6, with its expression being higher in the TRI6 mutants $(P<0.03)$ (Fig. 2). The Affymetrix data comparing a TRI6 mutant with its parental strain confirmed the positive regulation of FGSG_00007 and FGSG_10397 by TRI6 (Seong et al. 2009). These three new TRI6-regulated genes were located at different locations on $F$. graminearum chromosome 1 and 2 (as shown in Supplementary Fig. 2) and, thus, are not co-located with any TRI genes or any other readily identified gene cluster involved in secondary metabolism.
Among these new TRI6-regulated genes, FGSG_00007 encodes a cytochrome P450 monooxygenase with the closest amino acid sequence homology of known function being OrdA, a cytochrome P450 monooxygenase involved in Aflatoxin B1 and B2 biosynthesis in Aspergillus spp. (Prieto and Woloshuk 1997). Because OrdA is involved in the oxidation of the substrate $O$-methylsterigmatocystin (OMST) during aflatoxin biosynthesis (Prieto and Woloshuk 1997), the close homology between FGSG_00007 and OrdA makes FGSG_00007 a potential candidate for the oxidation of the $\mathrm{C} 8$ hydroxyl group of 7,8-dihydroxycalonectrin during DON biosynthesis. In fact, a gene for this function has not been identified to date in F. graminearum. Furthermore, homologues of FGSG_00007 could not be found in the $F$. sporotrichioides expressed sequence tag (EST) database at the National Center for Biotechnology Information (best match only $24 \%$ identical). The absence of a match for a gene encoding this function in $F$. sporotrichioides is expected because the T-2 toxin contains an isovaleryl group, not a carbonyl group, at the $\mathrm{C} 8$ position. This is in contrast to high levels of conservation between other cytochrome P450 monooxygenases between $F$. graminearum and $F$. sporotrichioides such as TRI11 (90\% identity) and the functionally slightly different TRI1 (64\% identity).

FGSG_10397 encodes a protein with a partial terpene cyclase domain (40\% aligned) with homology to trichodiene synthases such as TRI5. Although no terpene cyclase other than TRI5 is required for DON biosynthesis, structural similarities between enzymes that use or synthesize farnesyl diphosphate (Rynkiewicz et al. 2001) mean that FGSG_10397 may not necessarily be a terpene cyclase. No homologues of FGSG_10397 could be found among F. sporotrichioides EST.

\section{FGSG_00007 and FGSG_10397 mutants produce higher levels of DON.}

To determine the role of FGSG_00007 and FGSG_10397 in the biology of $F$. graminearum, these two genes were knocked out by replacing them with a neomycin resistance cassette using homologous recombination (Supplementary Figs. 4 and 5). Quantification of DON from FGSG_00007 and FGSG_10397 mutants grown in vitro showed large increases in the amount of DON produced under both noninducing (glutamine) and inducing (agmatine) conditions (Fig. 3). In some mutants,

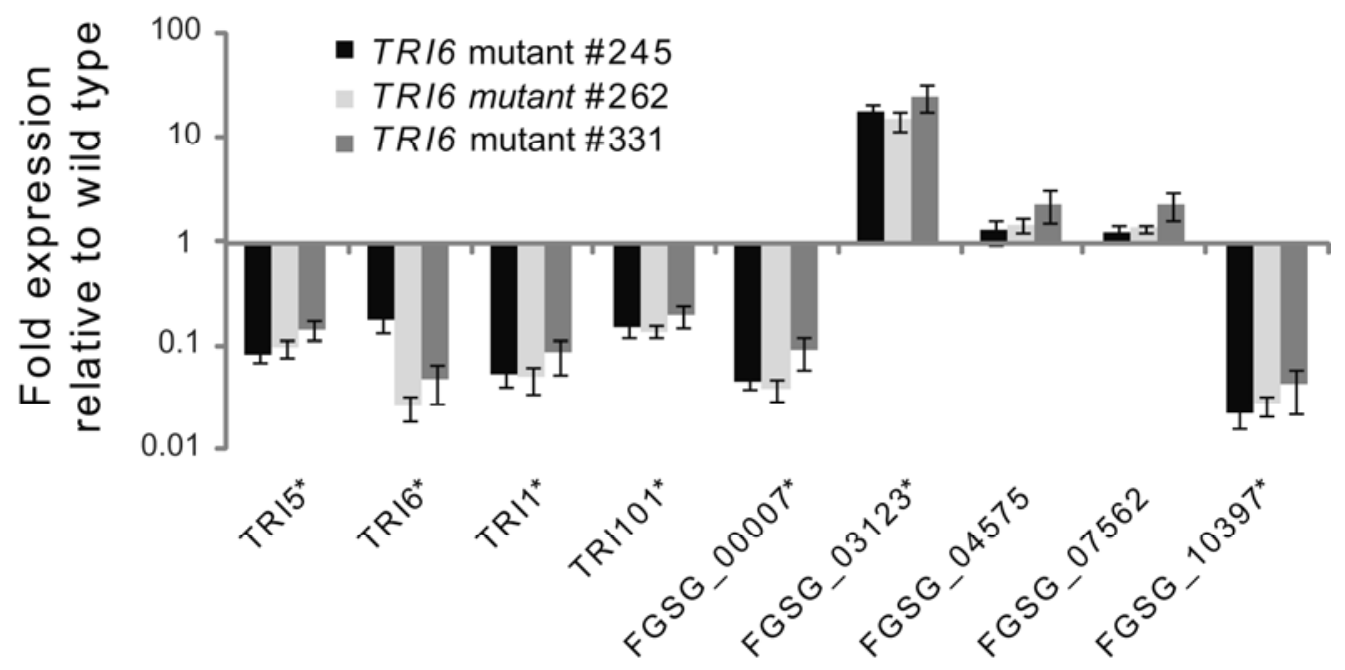

Fig. 2. Expression of TRI genes and putative TRI6 target genes in TRI6 mutant strains of Fusarium graminearum relative to that in the wild-type (parental) strain. Cultures were grown in media containing agmatine as the nitrogen source and harvested at 4 days postinoculation. Three independent mutants (nos. 245, 262, and 331) of TRI6 were used. Measurements were made using quantitative reverse-transcriptase polymerase chain reaction. Data are the mean of four biological replicates with error bars representing the standard error of the mean. Asterisks indicate statistically significant $(t$ test, $P<0.05)$ differential gene expression between the mutant and wild type for that particular gene in all three TRI6 mutants. 
DON at over 15,000 ppm was detected in media after 7 days of growth, which is approximately 14-fold higher than the average levels of DON produced by the wild-type parental strain under DON-inducing conditions. Even the levels of DON produced by these mutants in the typically noninducing glutamine approached those produced by the wild type under inducing conditions (Fig. 3). This increased DON production found in the two independent mutants for each gene was mediated, at least in part, by a greater than 10-fold increase in TRI5 (and presumably other TRI genes) expression in these mutant strains (Fig. 4). No obvious effects on the growth of the fungus in the culture were seen even at such high DON concentrations.

The gas chromatography-mass spectrometry (GC-MS) analysis of culture filtrates of FGSG_00007 mutants also showed that certain specific peaks from the parental toxin profiles were absent while some additional peaks were present in the toxin profiles (Fig. 5). The identity of most of these peaks is unknown but it is possible that many of the induced compounds

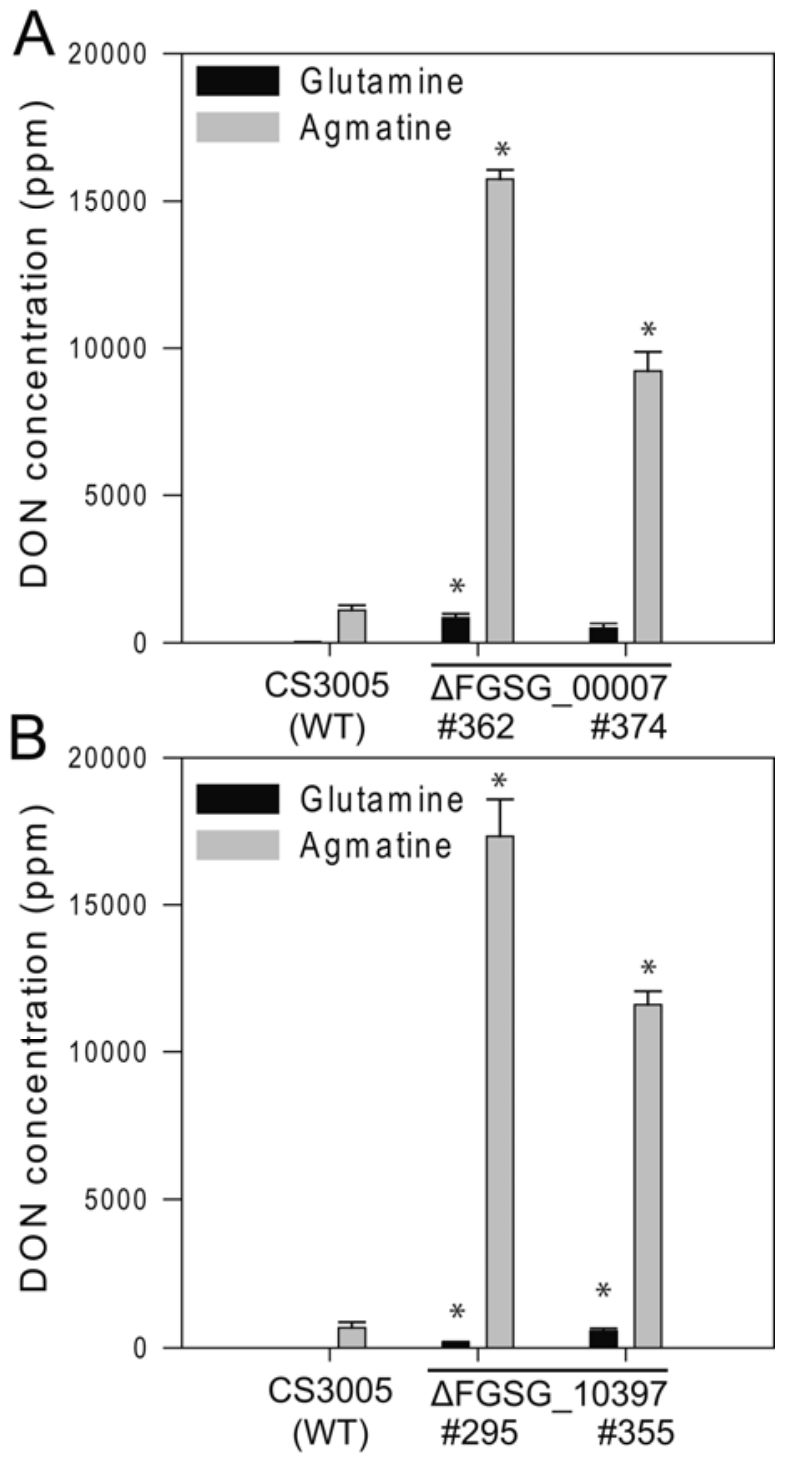

Fig. 3. Deoxynivalenol (DON) production by FGSG_00007 and FGSG_10397 mutants compared with the wild type. A, Wild type (CS3005) and FGSG_00007 mutants grown in glutamine and agmatine. B, Wild type and $F G S G \_10397$ mutants grown in glutamine and agmatine. Data are the mean of four biological replicates. Error bars are the standard error of the mean. Asterisks represent differences that were statistically significant $(t$ test, $P<0.05)$ compared with the wild type (CS3005) under the same conditions. are intermediates of DON biosynthesis because the flux through the pathway is expected to be much greater in the mutant than the wild type. These induced compounds also appeared to be absent from culture filtrate of the TRI6 mutant that does not produce trichothecenes (Fig. 5). GC-MS analysis also showed that the predominant form of DON produced in culture by both the wild type and the two mutants was 15ADON (Fig. 5) whereas the predominant form of toxin produced in planta by this isolate of $F$. graminearum and the mutants described here was DON (data not shown).

\section{FGSG_00007 and FGSG_10397 knock-out mutants show increased virulence.}

It has been well established that trichothecene production is required for full virulence of $F$. graminearum on wheat (Proctor et al. 1995a, 1997; Jansen et al. 2005). Therefore, we tested the virulence of these mutants on wheat using a point inoculation method of wheat heads. Both the FGSG_00007 and
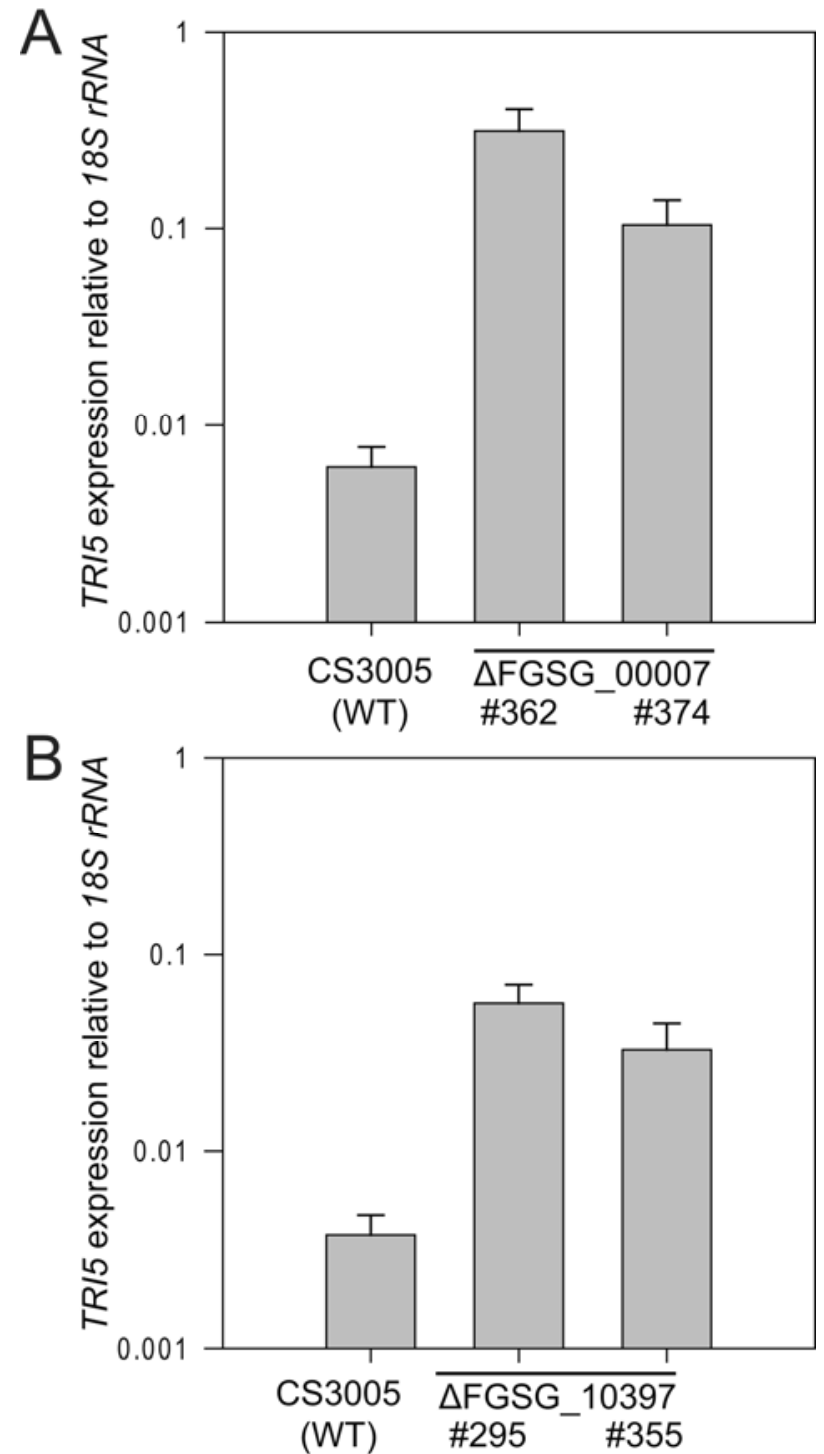

Fig. 4. TRI5 expression in the wild type and A, FGSG_00007 and B, FGSG_10397 mutant strains of Fusarium graminearum. Cultures were grown in defined media containing $5 \mathrm{mM}$ agmatine as the sole nitrogen source and cultures harvested for RNA extraction 4 days postinoculation. Data are the mean of four biological replicates with error bars representing the standard error of the mean. All comparisons to the relevant wild-type culture were statistically significant $(P<0.05)$, except for $F G S G \_10397$ mutant no. 355, for which $P=0.057$. 
FGSG_10397 mutants showed higher virulence toward FHBsusceptible wheat cv. Kennedy than the parental strain $(P<$ 0.0003 for FGSG_00007 and $P<0.0006$ for $F G S G \_10397$ ) (Fig. 6). The FGSG_00007 mutation also allowed F. graminearum to partially overcome the resistance to disease spread in wheat cv. Sumai $3 P=0.006$ ) (Fig. 7) but not the mutation in FGSG_10397, where a small increase in the mean disease score was observed; however, this was not statistically significant $(P=0.27)$.

To test whether the increased virulence of FGSG_00007 and FGSG_10397 mutants on Kennedy was associated with increased toxin production, DON was quantified from infected heads by GC-MS (Fig. 6C and F). Mutants in either gene showed statistically significant increases in toxin production $\left(P<0.005\right.$ for $F G S G \_00007$ and $P<0.003$ for $\left.F G S G \_10397\right)$.

\section{Gene clusters involved}

\section{in secondary metabolite biosynthesis are}

coordinately regulated by agmatine in $\boldsymbol{F}$. graminearum.

A close inspection of microarray data also indicated the coordinated expression of clusters of genes with predicted roles in secondary metabolism by agmatine. For instance, similar to many of the TRI genes, a gene cluster including the nonribosomal peptide synthetase NPS8, and genes containing a fatty acid moiety, showed agmatine or glutamine expression ratios of approximately 200-fold (Fig. 8A). This differential expression was validated for two of the genes from this cluster using qRT-PCR. The FG1 gene annotation for NPS 8 has been used instead of the FG3 gene model, which appears incorrect because the FG3 gene model splits NPS8 into two separate genes, omitting one of the seven modules that is encoded by an uninterrupted open reading frame in the FG1 model. We were interested to know whether the NPS8 gene cluster showed strong induction during plant infection when compared with that observed during growth in standard media, and published $F$. graminearum microarray datasets were analyzed to answer this question. In the data set of Güldener and associates (2006b), NPS 8 was expressed significantly higher in planta during FHB infection than in vitro. This was also the case for expression of this gene during crown rot disease of wheat stem bases caused by F. graminearum (Stephens et al. 2008).

Bioinformatic analysis of over-represented motifs in the promoter regions of genes that clustered with NPS8 (Fig. 8A) identified an element almost identical (Fig. 8B) to that found in the promoters of genes in gliotoxin and sirodesmin clusters (Fox et al. 2008). This motif was absent upstream of the four genes in this cluster that did not show induction by agmatine (Fig. 8A). The presence of the same regulatory motif identified in the promoters, together with the co-expression profiles of these genes by agmatine, suggest that this cluster extends across approximately $65 \mathrm{~kb}$ in the $F$. graminearum genome. However, the cluster is most probably interrupted by a region of approximately $10 \mathrm{~kb}$ that contains genes not co-regulated by agmatine. The identification of conditions under which this cluster is highly expressed now provides a starting point for determining the metabolite or metabolite produced by this group of genes. Based on the genes present in the cluster, it can be predicted that the relevant metabolite probably contains both peptide and fatty acyl moieties. The closest known Fusarium metabolite to this predicted metabolite is acuminatum produced by $F$. acuminatum, $F$. sporotrichioides, and $F$. tricinctum. Acuminatum contains a 14-carbon fatty acid chain and six amino acids (Flippin et al. 1989), although this is not known to be produced by $F$. graminearum.
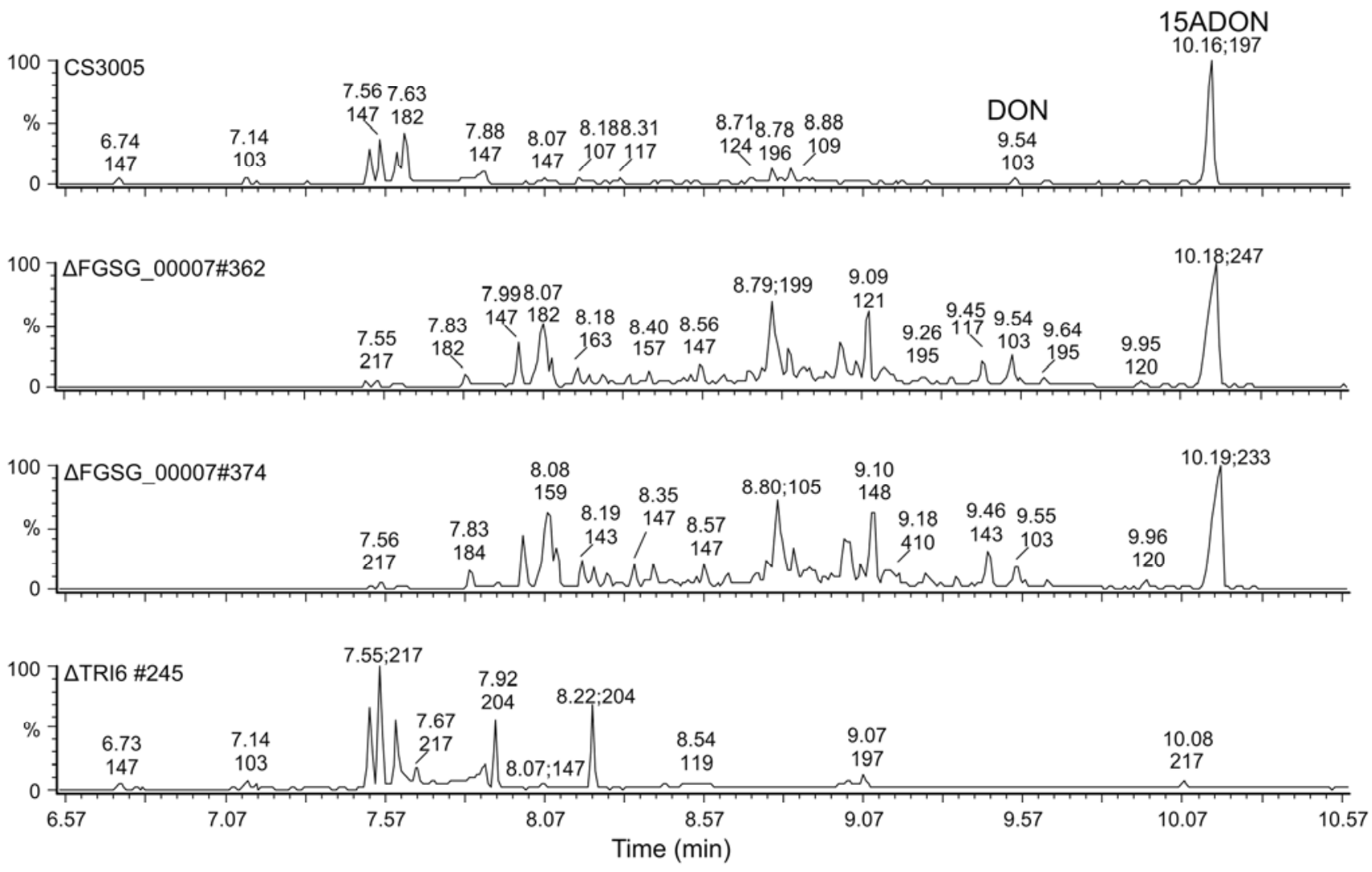

Fig. 5. Chromatograms of culture filtrate extracts from agmatine-grown cultures of the wild type (CS3005), FGSG_00007 mutants (nos. 362 and 374), and TRI6 mutant (no. 245). Deoxynivalenol (DON) and 15-ADON have retention times of approximately 9.55 and 10.16 min, respectively. A number of peaks were observed either only in the mutant or at much higher levels than in the wild type. 
Another group of genes that are co-regulated with the TRI genes in planta are the butenolide biosynthetic cluster (Harris et al. 2007), and two of these genes show high levels of induction by agmatine ( $F G S G \_08077$ and $F G S G \_08078,28-$ and 20-fold higher) compared with glutamine.
Finally, four other clusters of genes showed higher expression in glutamine than agmatine. These were the cluster for the golden yellow pigment aurofusarin but excluding the FgaflT and $\mathrm{ZnC}$ - $t f$ genes (Malz et al. 2005); a cluster containing PKS6 and NRPS7 (FGSG_08205-FGSG_08210); a cluster encoding
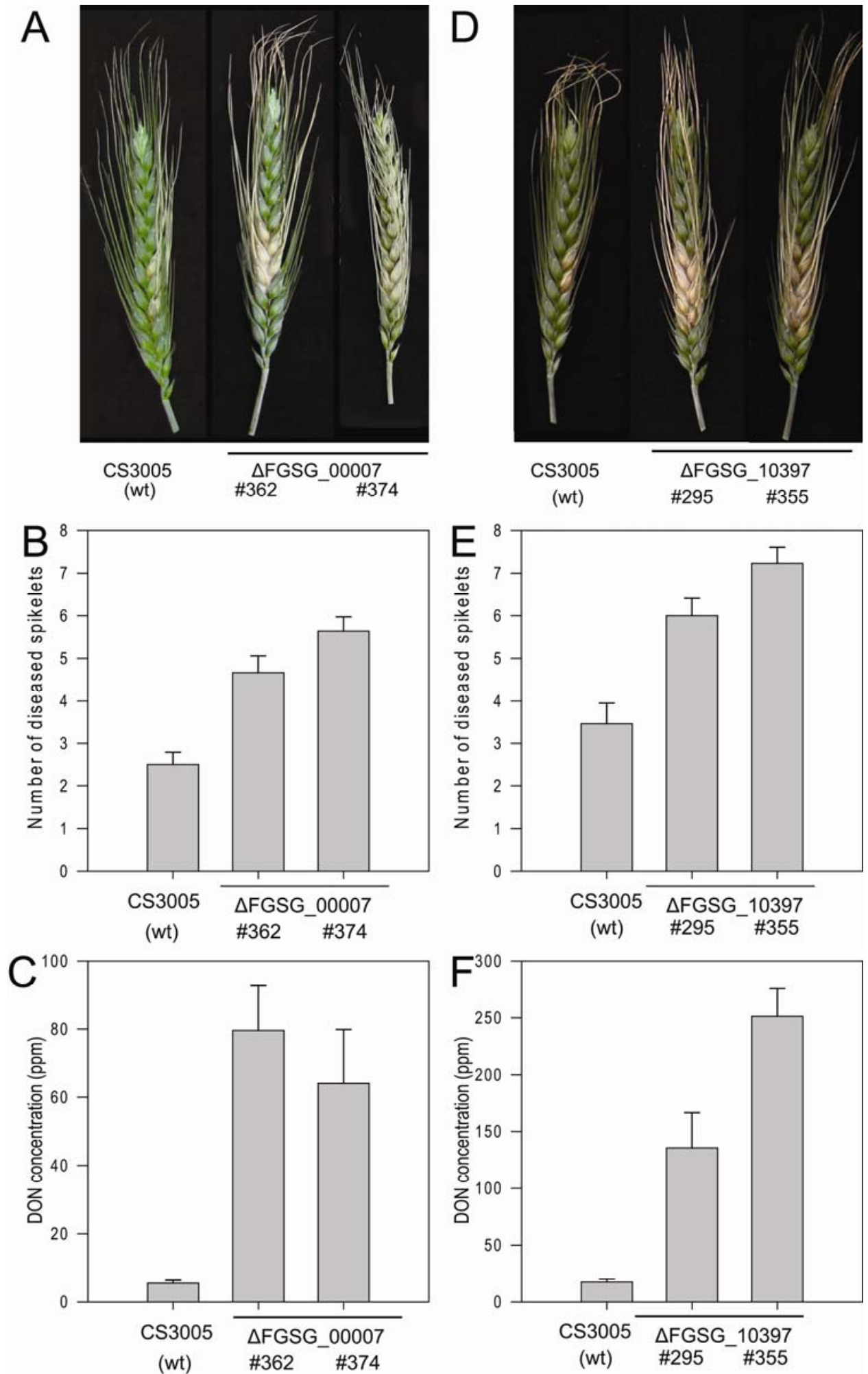

Fig. 6. Increased virulence and deoxynivalenol (DON) production during infection of FGSG_00007 and FGSG_10397 mutant strains of Fusarium graminearum. Heads were harvested 7 days postinoculation. A and D, Representative images of infected heads. B, C, E, and F, Averages from a minimum of 11 replicate heads with error bars representing the standard error of the mean. No infection or DON was observed in mock-infected samples conducted at the same time (data not shown). DON was the predominant trichothecene produced in planta, with only minor amounts of 15 -ADON being detected in some samples (data not shown). 
five cytochrome P450 monooxygenases, a TRI7 (acetyl transferase) paralogue, a hypothetical protein, and a protein with multiple transmembrane domains that, in yeast, is involved in resistance to xenobiotics (FGSG_02111-FGSG_02119); and a cluster containing five oxidoreductases of various classes, a prenyltransferase, and a hypothetical protein (FGSG10608FGSG10614).

Recently, there have been a number of observations in fungi that genes with potential roles in pathogenesis, such as those involved in secondary metabolism, may be preferentially located in subtelomeric or other chromosomal regions considered to be undergoing faster rates of evolution (Cuomo et al. 2007; McDonagh et al. 2008). Most NPS and PKS genes in $F$. graminearum are also located in or in very close proximity to genomic regions of high single-nucleotide polymorphism density or regions that show high genetic recombination rates (data not shown). Despite this, an analysis of genes that were differentially regulated by agmatine versus glutamine showed no statistically significant location preference for genomic regions with a high genetic recombination rate or polymorphism density (data not shown). This is in contrast to $F$. graminearum genes that show exclusive expression in planta or that encode secreted proteins (Cuomo et al. 2007), suggesting that, although agmatine induces TRI and other gene cluster expression, there may be major differences between agmatine-induced and global gene expression during FHB.

\section{DISCUSSION}

Nitrogen sources have been intensively studied as regulators of gene expression in fungi (Marzluf 1997), and basic nitrogen sources (such as nitrate, ammonium, or glutamine) are known to differentially regulate secondary metabolism in various fungi. We previously identified a variety of amines and amino acids that specifically induced DON biosynthesis when used as either a nitrogen source or added to cultures in combination with certain other permissive nitrogen sources (Gardiner et al. 2009a). In this study, analysis of global gene expression indicated that agmatine and glutamine differentially regulate a large number of genes in the $F$. graminearum genome. Genes involved in secondary metabolism were significantly represented among those showing higher expression in agmatine. In this report, we have identified two genes with putative functions in secondary metabolism that also have negative regulatory effects on DON biosynthesis and fungal virulence.

Many fungal secondary metabolite gene clusters contain genes that encode what are thought to be pathway-specific regulatory factors (Woloshuk et al. 1994; Proctor et al. 1995b; Fox et al. 2008). In the $F$. graminearum and $F$. sporotrichioides trichothecene production cluster, the transcription factor TRI6 not only regulates the genes involved in the central trichothecene biosynthesis pathway but also those involved in the upstream primary metabolite pathway (isoprenoid) and other seemingly unrelated genes (Peplow et al. 2003; Seong et al. 2009). In our study, the upregulation of the isoprenoid pathway genes was not observed in the comparison of toxin-inducing and -noninducing conditions (data not shown). The expression analysis conducted under DON-inducing conditions followed by bioinformatic analyses revealed new TRI6-regulated genes. Gene disruption performed here of two of these genes revealed an endogenous negative regulatory system for DON production. The elevated levels of DON produced by these mutants indicated that the products of these genes are either acting directly to limit DON production under certain conditions or are part of a competitive pathway for metabolic precursors of the trichothecene biosynthetic pathway. The massively elevated expression of TRI5 in FGSG_00007 and FGSG_10397 mu- tants may indicate that the products of these genes are responsible for producing a metabolite that negatively regulates DON production at the transcriptional level. The identity of such a metabolite is currently unknown.

Our findings of massively increased DON production in the knock-out mutants also indicate that $F$. graminearum has the capacity to produce much higher levels of trichothecenes than previously observed. There is an extensive body of literature that has demonstrated that trichothecenes are required for full virulence of Fusarium pathogens causing FHB on wheat (Proctor et al. 1995a, 1997; Jansen et al. 2005). The production of trichothecenes appears to be necessary for the pathogen to move from an infected floret via the rachis to another and spread through
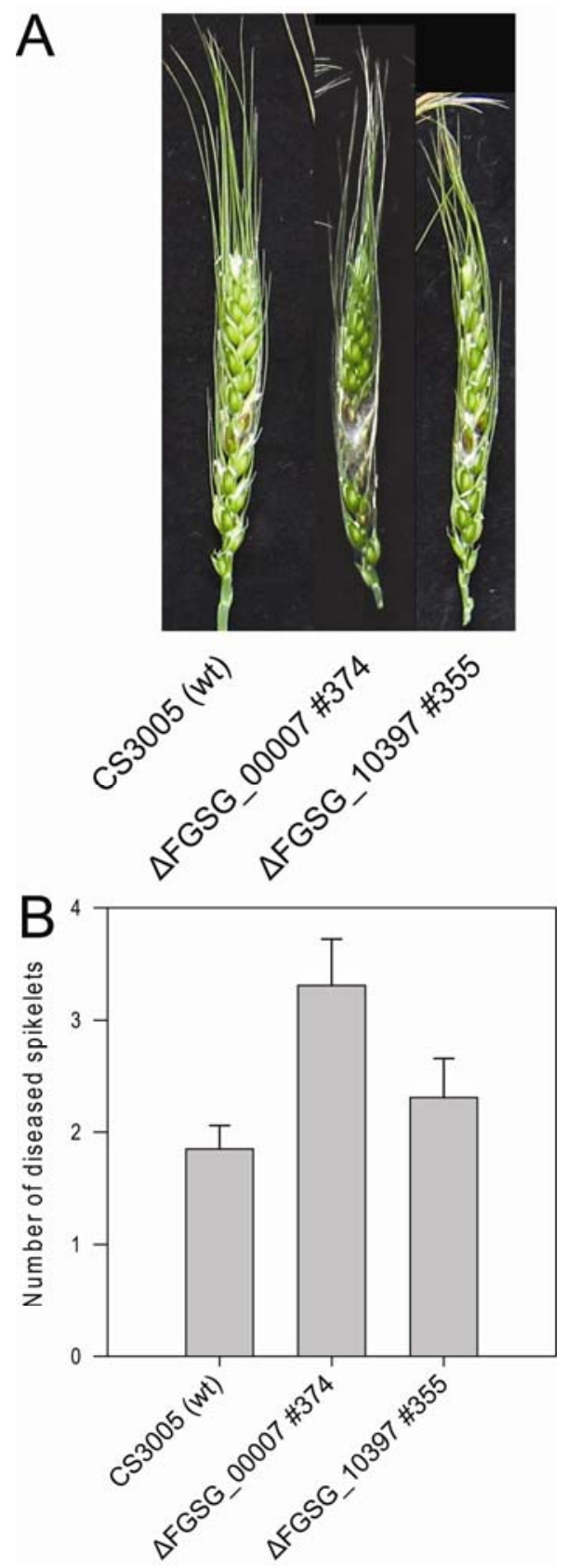

Fig. 7. Pathogenicity of wild-type (CS3005) and FGSG_00007 and FGSG_10397 mutant strains of Fusarium graminearum toward wheat cv. Sumai 3 . Heads were harvested 7 days postinoculation. A, Representative infected heads. B, Number of diseased spikelets. Error bars represent standard error of the mean $(n \geq 13)$. No infection or deoxynivalenol was observed in mock-infected samples conducted at the same time (data not shown). 
the head (Jansen et al. 2005). Therefore, it seems likely that the enhanced virulence of the FGSG_00007 and FGSG_10397 mutants is because of higher levels of production of trichothecenes, and this is consistent with the elevated levels observed in infected heads following inoculation with these mutants. The partially FHB-resistant wheat cv. Sumai 3 is thought to detoxify trichothecenes such as DON (Lemmens et al. 2005) and it is also likely that the increased DON-producing capacity of the FGSG_00007 mutant may explain its increased virulence on Sumai 3. However, the analysis of trichothecene profiles indicated that other secondary metabolites may accumulate in the mutant strains, and further research will be required to fully establish the role of trichothecene production in the virulence of the FGSG_00007 and FGSG_10397 mutants.

The fitness consequence of a loss-of-function mutation occurring in one of these genes in the pathogen in the field are unknown but our findings underline the potential for this pathogen to evolve with an ability to produce massively increased amounts of toxins and increased virulence. The widespread de- ployment of Sumai 3-derived resistance in wheat cultivars may provide increased selection pressure for these types of mutations. Recent findings studying TRI genes and trichothecene composition have suggested that shifts in gene composition and toxin profiles are occurring among $F$. graminearum populations in North America (Ward et al. 2008). The identification of alternative regulatory genes such as FGSG_00007 and $F G S G \_10397$ will provide additional loci for analysis in future population genetic studies.

In conclusion, this study has revealed a suite of genes that are co-regulated with TRI genes under culture conditions that induce high trichothecene production. Interestingly, two of the most strongly TRI6-dependent and agmatine-co-regulated genes appear to have a role in capping the production of trichothecenes because mutants produce massive quantities of these toxins and are hypervirulent on wheat. Future functional analysis of other genes identified here may reveal new insights into the regulation of toxin production and virulence in this economically important fungal pathogen.

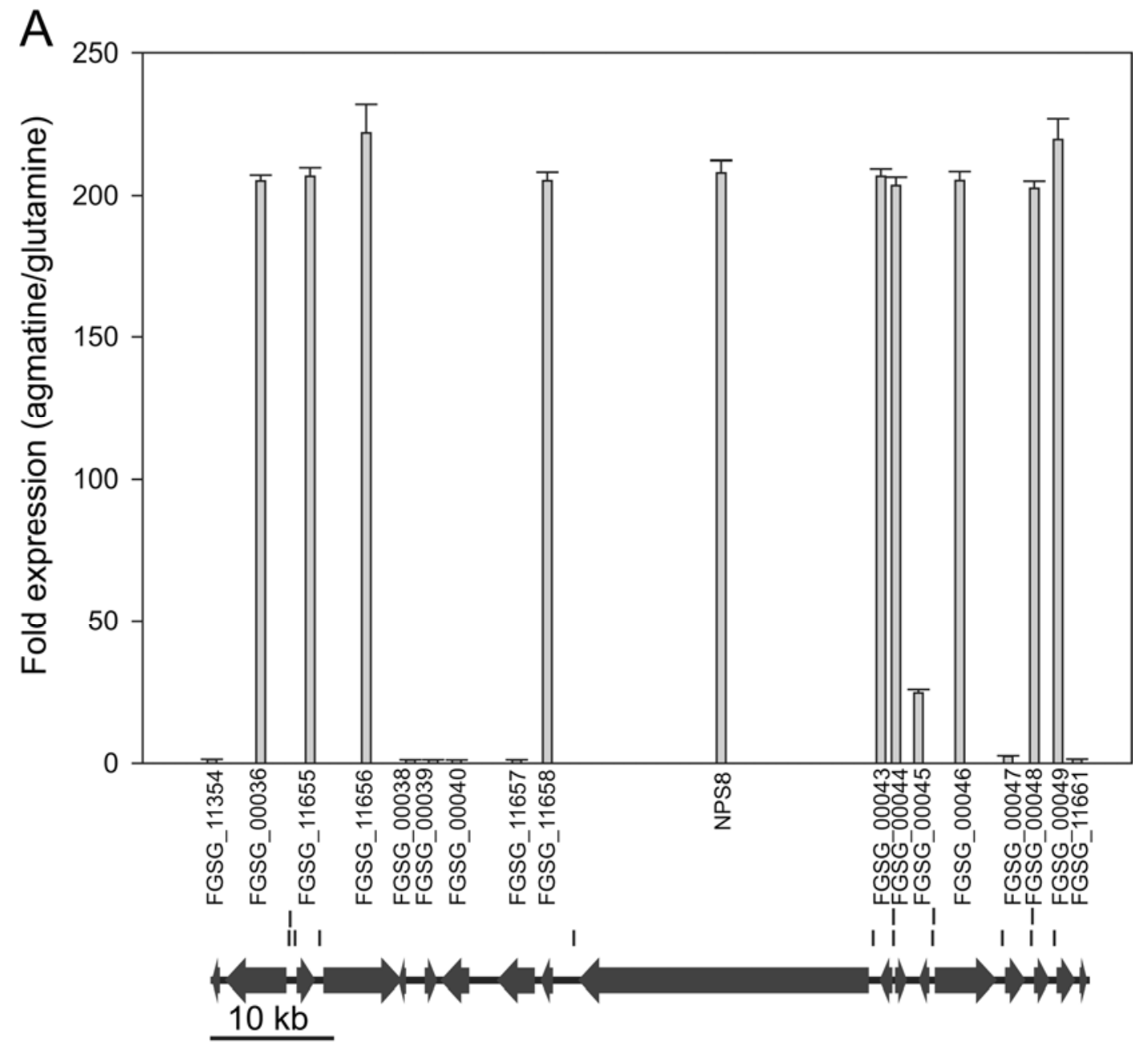

B

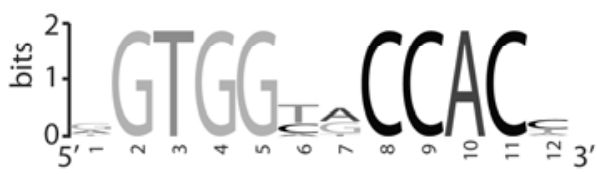

Fig. 8. A, Gene cluster containing NPS8 (encoding a seven-module peptide synthetase) that was upregulated in agmatine containing media as measured by Affymetrix analysis. B, Logo diagram of the overrepresented sequence in the upstream regions of genes in A. Vertical lines above the cluster diagram in A are instances of the GTGGNNCCAC palindrome in the $70 \mathrm{~kb}$ of sequence. 


\section{MATERIALS AND METHODS}

\section{Culture conditions.}

F. graminearum wild-type isolate CS3005 was grown in defined media containing either glutamine or agmatine (5 $\mathrm{mM}$ ) as described previously (Gardiner et al. 2009a). Growth of $F$. graminearum in glutamine and agmatine are similar $(P=$ $0.38)$. For the microarray experiment, each replicate consisted of mycelia pooled from six separate wells of a 96-well plate. Four replicates were used for each treatment, with the glutamine and agmatine treatments occurring in separate 96well plates. The glutamine-grown samples are the same samples as those described as a mycelia reference by Stephens and associates (2008). For experiments with TRI6 mutant strains, replicates consisted of mycelia pooled from two separate wells. Unused wells in all experiments were filled with sterile water to prevent evaporation. Cultures for toxin profiling using GC-MS analysis were grown in $20 \mathrm{ml}$ of defined media containing agmatine (Gardiner et al. 2009a) in 9-cm-diameter deep petri dishes for 7 days prior to filtrate harvest.

\section{RNA extraction and hybridizations.}

Mycelia were harvested 4 days postinoculation, snap frozen, and freeze dried prior to RNA extraction. RNA was extracted using the QIAgen (Hilden, Germany) RNeasy plant mini kit according to the manufacturer's instructions, including the on-column DNaseI treatment. RNA integrity analyses, labeling, and hybridization to Affymetrix Fusarium GeneChips was performed at the Australian Genome Research Facility (Melbourne, Australia) according to the standard Affymetrix protocols.

\section{Microarray data analysis.}

CEL files were imported in the GeneSpring 7.3 (Silicon Genetics, Santa Clara, CA, U.S.A.) and RMA preprocessing applied. All signals below 0.01 were converted to 0.01 and data normalized by converting per-chip normalizations to the 50th percentile and per-gene normalizations to the median. To determine differentially regulated genes, $t$ tests were used with Benjamini and Hochberg false discovery rate multiple testing corrections applied. Additional fold-expression filters were applied as described in the results.

The probe sets present on the Fusarium Affymetrix GeneChips (Santa Clara, CA, U.S.A.) were designed from the MIPS annotation of the first assembly of the $F$. graminearum genome. These were converted to FG3-compatible annotations using the alias conversion downloadable from the MIPS $F$. graminearum website. Where multiple probe sets mapped to the same FG3 gene, the annotation hierarchy described by Güldener and associates (2006b) was used. Data (CEL) files can be found at PLEXdb under experiment FG14. Functional classification of gene products and analysis for enriched classes of gene products were performed using the FunCat system at MIPS as described previously (Güldener et al. 2006a). This analysis uses the hypergeometric distribution to determine probabilities associated with enrichment of classes of gene products in a given data set compared with the genome as a whole as described by Seong and associates (2008).

\section{qRT-PCR.}

qRT-PCR was performed as previously described (Mudge et al. 2006) using $18 S r R N A$ as a reference. Primer sequences are listed in Table 2. To determine the significance of differences in gene expression observed between wild-type and mutant strains, $t$ tests were used.
DON measurements.

DON concentration in the culture medium was measured using the DON Plate Kit ELISA from Beacon Analytical Systems (Portland, ME, U.S.A.) according to the manufacturer's instructions. Sequential 10-fold dilutions in water of the culture medium were made for samples outside the quantification range until an in-range reading was obtained.

DON concentrations in infected plant material were determined using GC-MS. The GC-MS instrumentation used comprised a PerkinElmer autosampler XL and gas chromatograph and Turbomass Upgrade MS (Waltham, MA, U.S.A.). The MS was tuned according to the manufacturer's recommendations using perfluorotributylamine. GC was carried out on an Agilent Technologies (Santa Clara, CA, U.S.A.) DB5M5 column of $30 \mathrm{~m}$ in length, internal diameter of $0.25 \mathrm{~mm}$, and a film size of $0.25 \mu \mathrm{m}$. Temperatures were maintained at $300^{\circ} \mathrm{C}$ for the injector port, $200^{\circ} \mathrm{C}$ for the transfer line, and $200^{\circ} \mathrm{C}$ for the ion source. The oven temperature was initially set at $80^{\circ} \mathrm{C}$ for $1 \mathrm{~min}$, ramped at $25^{\circ} \mathrm{C} / \mathrm{min}$ to $280^{\circ} \mathrm{C}$, then maintained at $280^{\circ} \mathrm{C}$ for $6 \mathrm{~min}$. Helium was used as the carrier gas at a flow rate of $1 \mathrm{ml} \mathrm{min}^{-1}$. Data was collected from m/z 90 to 605 in the positive ion mode $(70 \mathrm{eV})$. Culture filtrates $(750 \mu \mathrm{l})$ were extracted in ethyl acetate/methanol/filtrate $(4: 1: 3, \mathrm{vol} / \mathrm{vol} / \mathrm{vol})$ (He et al. 2007). The supernatant was dried under nitrogen and derivatized with $20 \mu \mathrm{l}$ of TMSI/TMCS as described previously (Mirocha et al. 1998). The organic phase $(1 \mu \mathrm{l})$ was injected in split-less mode.

To determine the significance of differences in DON production observed between wild-type and mutant strains, $t$ tests were used.

\section{Promoter sequence analysis.}

MEME and MAST motif discovery and searching tools (Bailey and Elkan 1994; Bailey and Gribskov 1998) were applied to the data sets as described by Fox and associates (2008). For the prediction of transcripts with putative TRI6 binding sites, the promoters of all known TRI genes were used as input into MEME to generate de novo a position-dependent letter-probability matrix. This matrix, which matched the known TRI6 binding site consensus YNAGGCC(T) (Hohn et al. 1999), was used to search sets of promoter sequences for putative TRI6 binding sites with the MAST program.

\section{Vector construction and fungal transformation.}

Genomic regions (4 to $6 \mathrm{~kb}$ ) surrounding the target locus were amplified using primers specified in Table 2 using Phusion DNA polymerase (Finnzymes, Woburn, MA, U.S.A.), Atailed with Taq DNA polymerase, and cloned into pCR8GW/TOPO (Invitrogen, Carlsbad, CA, U.S.A.). Resulting plasmids were introduced into Escherichia coli DY380 to allow introduction of the geneticin resistance cassette using lambda phage protein-mediated recombination (Lee et al. 2001). The geneticin resistance cassette was constructed in DY380 as follows. The aminoglycoside $3^{\prime}$-phosphotransferase (nptII) resistance cassette and herpes simplex virus thymidine kinase terminator $\left(\mathrm{T}_{\mathrm{HSV} t \mathrm{t}}\right)$ from pEGFP-N1 (Clontech, Mountain View, CA, U.S.A.) was amplified (primers BLAnptF and AMPtkR) and used to replace the ampicillin resistance cassette in pUC19 (Invitrogen), with the resultant construct having nptII driven by the BLA bacterial promoter $\left(\mathrm{P}_{\mathrm{BLA}}\right)$. The resulting $\mathrm{P}_{\mathrm{BLA}}$-nptII- $\mathrm{T}_{\mathrm{HSVtk}}$ was amplified (primers GPDBla and pUCtkR) and the product used to replace the hygromycin phosphotransferase coding sequence and TrpC terminator from pAN7.1 (GenBank Z32698) to give a $\mathrm{P}_{\mathrm{GPDA}}-\mathrm{P}_{\mathrm{BLA}}-n$ tII- $\mathrm{T}_{\mathrm{HSVtk}}$ cassette to allow selection in both bacteria (kanamycin) and fungi (geneticin). At each step after amplification of PCR products generated with long primers, products were DpnI 
digested and precipitated in $10 \% \mathrm{PEG}_{8000}$ and $10 \mathrm{mM} \mathrm{MgCl}_{2}$, then washed with $70 \%$ ethanol before introduction into DY380 as described (Lee et al. 2001). Fungal transformation was carried out according to Desmond and associates (2008) using circular plasmids. Deletion sizes were $340,1,045$, and 520 bp internal to the coding sequence for TRI6, FGSG_00007, and FGSG_10397, respectively. Targeted deletion was confirmed by PCR and toxin analyses for TRI6 (Supplementary Fig. 3) and PCR and Southern analysis for FGSG_00007 and FGSG_10397.

Table 2. Primers used for generation of targeting constructs, quantitative reverse-transcriptase polymerase chain reaction (qRT-PCR), and PCR screening of transformants for gene knockouts ${ }^{\mathrm{a}}$

\begin{tabular}{|c|c|c|}
\hline Primer & Purpose & Sequence $\left(5^{\prime} \rightarrow 3^{\prime}\right)$ \\
\hline BLAnptF & $\begin{array}{l}\text { Replace } \beta \text {-lactamase cassette in pUC19 with } \\
\text { nptII-HSV-tk cassette from pEGFP-N1 }\end{array}$ & tgagacaataaccctgataaatgcttcaataatattgaaaaaggaagagtATGATTGAACAAGATGG \\
\hline AMPtkR & & tgaagttttaaatcaatctaaagtatatatgagtaaacttggtctgacagTAACCTGAGGCTATGG \\
\hline GPDBla & $\begin{array}{l}\text { Replace HPH-TrpC terminator from pAN7.1 } \\
\text { with BLA-nptII-HSV-tk }\end{array}$ & cacttcatcgcagcttgactaacagctacccegcttgagcagacatcaccCCTGATAAATGCTTCAA \\
\hline pUCtkR & $\ldots$ & cagggttttccagtcacgacgttgtaaaacgacggecagtgccaagcttTAACCTGAGGCTATGG \\
\hline FGSG_00007KOr2 & $\begin{array}{l}\text { Amplify homology region for } \mathrm{Fg} 00007 \\
\text { knockout }\end{array}$ & AAGCATCAAATGGGAAAACG \\
\hline FGSG_00007KOf2 & $\ldots$ & TTGTAGTAGGGGCACCAAGG \\
\hline FGSG_00007nptF & $\begin{array}{l}\text { Amplify selectable marker for } F g 00007 \\
\text { knockout }\end{array}$ & atcagccaactttggaggtagattgtgcggttttgaccagattttgagtcAGAAGAACTGGAGGGGTGGT \\
\hline FGSG_00007nptR & $\ldots$ & tcaaatgctgctacaacacgagcgatgacaataaaatactctcatcggcTAACCTGAGGCTATGG \\
\hline TRI6KOf & Amplify homology region for TRI6 knockout & CGGTGTGCATGAAATAGGTG \\
\hline TRI6KOr & $\ldots$ & AGCGATTGGTGCTAGATGCT \\
\hline TRI6nptF & Amplify selectable marker for TRI6 knockout & atctaaacgactatgaatcaccaacattcgaaatagatcttctctcagaaAGAAGAACTGGAGGGGTGGT \\
\hline TRI6nptR & $\ldots$ & agactcatgccgagcacggtcettgcgagtcgcaaagcetttggtgccgaTAACCTGAGGCTATGG \\
\hline FGSG_10397KOf & Amplify homology region for $F g 10397$ & \\
\hline & knockout & GTTGGGTTCAGCGGGTAGTA \\
\hline FGSG_10397KOr & $\ldots$ & GCAAATGGCTTGGGTACAGT \\
\hline FGSG_10397nptF & $\begin{array}{l}\text { Amplify selectable marker for } F g 10397 \\
\text { knockout }\end{array}$ & attcgaggtttctcacggatcttgatctacagccggaatatagacgtcacAGAAGAACTGGAGGGGTGGT \\
\hline FGSG_10397nptR & $\ldots$ & cgaagtagttgectccetttgatggatgatcaccettttctttaatacccTAACCTGAGGCTATGG \\
\hline $18 \mathrm{Sf}$ & qRT-PCR & GTCCGGCCGGGCCTTTCC \\
\hline $18 \mathrm{Sr}$ & $\ldots$ & AAGTCCTGTTTCCCCGCCACGC \\
\hline$\beta$-tubulinf & qRT-PCR & GTCATTACACCGAGGGTGCT \\
\hline$\beta$-tubulinr & $\ldots$ & CCACCAAGAGAGTGGGTGAT \\
\hline TRI4f & qRT-PCR & TATTGTTGGCTACCCCAAGG \\
\hline TRI4r & $\ldots$ & GCCTTGAGAACCTTGACTCG \\
\hline TRI5f & qRT-PCR & CACTTTGCTCAGCCTCGCC \\
\hline TRI5r & $\ldots$ & CGATTGTTTGGAGGGAAGCC \\
\hline TRI6f & qRT-PCR & TTACATGGAGGCCGAATCTC \\
\hline TRI6r & $\ldots$ & AAAGTCCTTGGCAGGATCG \\
\hline TRI1f & qRT-PCR & TGGCACAAGATTCGACTCAG \\
\hline TRI1r & $\ldots$ & AGCGTATTCCGAAGTGATGC \\
\hline TRI101f & qRT-PCR & GAAAGAATCGATGGCTCTGC \\
\hline TRI101r & $\ldots$ & AGTGACTCGTTGGCGATTTC \\
\hline FGSG_00036f & qRT-PCR & CATGGCGCAGATAAAAACCT \\
\hline FGSG_00036r & $\ldots$ & TCTGCCTGAATTTGCTGTTG \\
\hline FGSG_00048f & qRT-PCR & TTCTCGGACAGCCTCTGTTT \\
\hline FGSG_00048r & $\ldots$ & ACCATGACTCCCATCCTCAG \\
\hline FGSG_00007f & qRT-PCR & GGCCGACGATGACATCTACT \\
\hline FGSG_00007r & $\ldots$ & TTTCTGGGTTGTGGAGGAAC \\
\hline FGSG_03123f & qRT-PCR & CCATCCACGACGGTACTCTT \\
\hline FGSG_03123r & $\ldots$ & CGTCGGTTGTCAACTCAGAA \\
\hline FGSG_04575f & qRT-PCR & TGGTGACGAGAGCAATTCAG \\
\hline FGSG_04575r & $\ldots$ & TTCAGCATCCCCTCAATACC \\
\hline FGSG_07562f & qRT-PCR & TCACATTCAAGCAGGTCTGG \\
\hline FGSG_07562r & $\ldots$ & CGATGTTGGGTGTCATCTTG \\
\hline FGSG_10397f & qRT-PCR & GGGTGATCATCCATCAAAGG \\
\hline FGSG_10397r & $\ldots$ & GTCGTTTGGGGAAAGTGAAC \\
\hline FGSG_10613f & qRT-PCR & GCTCCATTTCAGAGGTGCTC \\
\hline FGSG_10613r & $\ldots$ & GGCGCATCTACCAAGTCATT \\
\hline 292 & TRI6 mutant PCR screening assay & GACGCGTCTCGGATAAGAAT \\
\hline 293 & $\ldots$ & TGGGGAAGTTGTCAAAGTCA \\
\hline 294 & $\begin{array}{l}\text { Mutant PCR screening assays. Binds in } g p d A \\
\text { promoter region }\end{array}$ & ACGTTTGACTTGCATTGTGC \\
\hline 295 & FGSG_10397 mutant PCR screening assay & GGTTCTCCTAACCGGTTTCA \\
\hline 296 & $\ldots$ & TGGGAGGCAGTTCTGAAAAT \\
\hline 297 & FGSG_00007 mutant PCR screening assay & TTCTTCCACCTCGCACTTCT \\
\hline 298 & $\ldots$ & TATCAAGAGAGCGCAGCAGA \\
\hline 430 & FGSG_10397 probe & CGGGTAGAAGGCAATATGGA \\
\hline 431 & $\ldots$ & GGCTTGGCGACTATTGTGAT \\
\hline 498 & $F G S G \_00007$ probe & AAGCCAAGGAATGCAAAGTG \\
\hline 499 & $\ldots$ & TCCACTCCGCTGACTAACCT \\
\hline
\end{tabular}

${ }^{\text {a }}$ Sequences in capitals in long primers are the regions of priming, with the lowercase letters regions of homology to target plasmids for recombination in Escherichia coli DY380. 
Plant growth and virulence assays.

The FHB-susceptible wheat cv. Kennedy and partially resistant Sumai 3 were grown in a glasshouse maintained at $24^{\circ} \mathrm{C}$ and $60 \%$ relative humidity during the day and $15^{\circ} \mathrm{C}$ and $90 \%$ relative humidity during the night in a 1:1 mix of sand and peat with added osmocote fertilizer in $15-\mathrm{cm}$ pots with two seeds per pot. At the time of anthesis plants, were moved to a containment facility for infection maintained at a constant temperature of $25^{\circ} \mathrm{C}$, with fluorescent lighting provided for 16 $\mathrm{h} /$ day. Heads at midanthesis were inoculated at a single central spikelet with $10 \mu \mathrm{l}$ of a suspension of macroconidia at $1 \times 10^{6}$ spores $\mathrm{ml}^{-1}$ prepared from strains grown for 7 days on synthetic nutrient-poor agar plates $\left(\mathrm{KH}_{2} \mathrm{PO}_{4}\right.$ at $1 \mathrm{~g} \mathrm{liter}^{-1}, \mathrm{KNO}_{3}$ at $1 \mathrm{~g} \mathrm{liter}^{-1}, \mathrm{MgSO}_{4} \cdot 7 \mathrm{H}_{2} \mathrm{O}$ at $0.5 \mathrm{~g} \mathrm{liter}^{-1}, \mathrm{KCl}$ at $0.2 \mathrm{~g} \mathrm{liter}^{-1}$, sucrose at $0.2 \mathrm{~g} \mathrm{liter}^{-1}$, glucose at $0.2 \mathrm{~g} \mathrm{liter}^{-1}$, and $2 \%$ [wt/vol] agar). Inoculated heads were covered with a humidified plastic zip lock bag for 3 days, after which they were covered with a glassine bag. Heads were harvested at 7 days postinoculation. Disease severity was scored by counting the total number of spikelets showing symptoms. To determine the significance of differences observed between wild-type and mutant strains, $t$ tests were used.

\section{ACKNOWLEDGMENTS}

This work was partially funded by Biogemma. We thank U. Güldener for providing various files related to the annotation of the $F$. graminearum genome; J. Antoniw, M. Urban, and K. Hammond-Kosack for providing OmniMapFree software; and A. Rusu for technical assistance with pathology assays and GC-MS analyses.

\section{LITERATURE CITED}

Alexander, N. J., McCormick, S. P., Larson, T. M., and Jurgenson, J. E. 2004. Expression of Tri15 in Fusarium sporotrichioides. Curr. Genet. 45:157-162

Bailey, T. L., and Elkan, C. 1994. Fitting a mixture model by expectation maximization to discover motifs in biopolymers. Proc. Int. Conf. Intell. Syst. Mol. Biol. 2:28-36.

Bailey, T. L., and Gribskov, M. 1998. Combining evidence using p-values: Application to sequence homology searches. Bioinformatics 14:48-54.

Cumagun, C. J. R., Bowden, R. L., Jurgenson, J. E., Leslie, J. F., and Miedaner, T. 2004. Genetic mapping of pathogenicity and aggressiveness of Gibberella zeae (Fusarium graminearum) toward wheat. Phytopathology 94:520-526.

Cuomo, C. A., Güldener, U., Xu, J.-R., Trail, F., Turgeon, B. G., Di Pietro, A., Walton, J. D., Ma, L.-J., Baker, S. E., Rep, M., Adam, G., Antoniw, J., Baldwin, T., Calvo, S., Chang, Y.-L., DeCaprio, D., Gale, L. R., Gnerre, S., Goswami, R. S., Hammond-Kosack, K., Harris, L. J., Hilburn, K., Kennell, J. C., Kroken, S., Magnuson, J. K., Mannhaupt, G., Mauceli, E., Mewes, H.-W., Mitterbauer, R., Muehlbauer, G., Munsterkotter, M., Nelson, D., O’Donnell, K., Ouellet, T., Qi, W., Quesneville, H., Roncero, M. I. G., Seong, K.-Y., Tetko, I. V., Urban, M., Waalwijk, C., Ward, T. J., Yao, J., Birren, B. W., and Kistler, H. C. 2007. The Fusarium graminearum genome reveals a link between localized polymorphism and pathogen specialization. Science 317:1400-1402.

Desjardins, A. E. 2006. Fusarium Mycotoxins: Chemistry, Genetics, and Biology. The American Phytopathological Society, St. Paul, MN, U.S.A.

Desmond, O. J., Manners, J. M., Stephens, A. E., Maclean, D. J., Schenk, P. M., Gardiner, D. M., Munn, A. L., and Kazan, K. 2008. The Fusarium mycotoxin deoxynivalenol elicits hydrogen peroxide production, programmed cell death and defence responses in wheat. Mol. Plant Pathol. 9:435-445.

Dyer, R. B., Plattner, R. D., Kendra, D. F., and Brown, D. W. 2005. Fusarium graminearum TRII4 is required for high virulence and DON production on wheat but not for DON synthesis in vitro. J. Agric. Food Chem. 53:9281-9287.

Flippin, L. A., Jalali-Araghi, K., Brown, P. A., Burmeister, H. R., and Vesonder, R. F. 1989. Structure of the fatty acid component of an antibiotic cyclodepsipeptide complex from the genus Fusarium. J. Org. Chem. 54:3006-3007.

Fox, E. M., Gardiner, D. M., Keller, N. P., and Howlett, B. J. 2008. A $\mathrm{Zn}(\mathrm{II})_{2} \mathrm{Cys}_{6}$ DNA binding protein regulates the sirodesmin PL biosyn- thetic gene cluster in Leptosphaeria maculans. Fungal Genet. Biol. 45:671-682.

Gaffoor, I., Brown, D. W., Plattner, R., Proctor, R. H., Qi, W., and Trail, F. 2005. Functional analysis of the polyketide synthase genes in the filamentous fungus Gibberella zeae (anamorph Fusarium graminearum). Eukaryot. Cell 4:1926-1933.

Gardiner, D. M., Kazan, K., and Manners, J. M. 2009a. Nutrient profiling reveals potent inducers of trichothecene biosynthesis in Fusarium graminearum. Fungal Genet. Biol. 46:604-613.

Gardiner, D. M., Osborne, S., Kazan, K., and Manners, J. M. 2009b. Low $\mathrm{pH}$ regulates the production of deoxynivalenol by Fusarium graminearum. Microbiology 155:3149-3156.

Goswami, R. S., and Kistler, H. C. 2004. Heading for disaster: Fusarium graminearum on cereal crops. Mol. Plant Pathol. 5:515-525.

Güldener, U., Mannhaupt, G., Munsterkotter, M., Haase, D., Oesterheld, M., Stumpflen, V., Mewes, H.-W., and Adam, G. 2006a. FGDB: A comprehensive fungal genome resource on the plant pathogen Fusarium graminearum. Nucleic Acids Res. 34:D456-458.

Güldener, U., Seong, K.-Y., Boddu, J., Cho, S., Trail, F., Xu, J.-R., Adam, G., Mewes, H.-W., Muehlbauer, G. J., and Kistler, H. C. 2006b. Development of a Fusarium graminearum Affymetrix GeneChip for profiling fungal gene expression in vitro and in planta. Fungal Genet. Biol. 43:316-325.

Harris, L. J., Alexander, N. J., Saparno, A., Blackwell, B., McCormick, S. P., Desjardins, A. E., Robert, L. S., Tinker, N., Hattori, J., Piche, C., Schernthaner, J. P., Watson, R., and Ouellet, T. 2007. A novel gene cluster in Fusarium graminearum contains a gene that contributes to butenolide synthesis. Fungal Genet. Biol. 44:293-306.

He, J., Yang, R., Zhou, T., Tsao, R., Young, J.C., Zhu, H., Li, X.-Z., and Boland, G. J. 2007. Purification of deoxynivalenol from Fusarium graminearum rice culture and mouldy corn by high-speed counter-current chromatography. J. Chromatogr. 1151:187-192.

Hohn, T. M., and Beremand, P. D. 1989. Isolation and nucleotide sequence of a sesquiterpene cyclase gene from the trichothecene-producing fungus Fusarium sporotrichioides. Gene 79:131-138.

Hohn, T. M., McCormick, S. P., and Desjardins, A. E. 1993. Evidence for a gene cluster involving trichothecene-pathway biosynthetic genes in Fusarium sporotrichioides. Curr. Genet. 24:291-295.

Hohn, T. M., Krishna, R., and Proctor, R. H. 1999. Characterization of a transcriptional activator controlling trichothecene toxin biosynthesis. Fungal Genet. Biol. 26:224-235.

Jansen, C., von Wettstein, D., Schafer, W., Kogel, K.-H., Felk, A., and Maier, F. J. 2005. Infection patterns in barley and wheat spikes inoculated with wild-type and trichodiene synthase gene disrupted Fusarium graminearum. Proc. Natl. Acad. Sci. U.S.A. 102:16892-16897.

Kimura, M., Kaneko, I., Komiyama, M., Takatsuki, A., Koshino, H., Yoneyama, K., and Yamaguchi, I. 1998. Trichothecene 3-O-acetyltransferase protects both the producing organism and transformed yeast from related mycotoxins. Cloning and characterization of Tri101. J. Biol. Chem. 273:1654-1661.

Lee, E. C., Yu, D., Martinez de Velasco, J., Tessarollo, L., Swing, D. A., Court, D. L., Jenkins, N. A., and Copeland, N. G. 2001. A highly efficient Escherichia coli-based chromosome engineering system adapted for recombinogenic targeting and subcloning of BAC DNA. Genomics 73:56-65.

Lee, J., Jurgenson, J. E., Leslie, J. F., and Bowden, R. L. 2008. Alignment of genetic and physical maps of Gibberella zeae. Appl. Environ. Microbiol. 74:2349-2359.

Lee, T., Han, Y.-K., Kim, K.-H., Yun, S.-H., and Lee, Y.-W. 2002. Tri13 and Tri7 determine deoxynivalenol- and nivalenol-producing chemotypes of Gibberella zeae. Appl. Environ. Microbiol. 68:2148-2154.

Lemmens, M., Scholz, U., Berthiller, F., Dall'Asta, C., Koutnik, A., Schuhmacher, R., Adam, G., Buerstmayr, H., Mesterházy, Ã., Krska, R., and Ruckenbauer, P. 2005. The ability to detoxify the mycotoxin deoxynivalenol colocalizes with a major quantitative trait locus for Fusarium head blight resistance in wheat. Mol. Plant-Microbe Interact. 18:1318-1324.

Malz, S., Grell, M. N., Thrane, C., Maier, F. J., Rosager, P., Felk, A., Albertsen, K. S., Salomon, S., Bohn, L., Schäfer, W., and Giese, H. 2005. Identification of a gene cluster responsible for the biosynthesis of aurofusarin in the Fusarium graminearum species complex. Fungal Genet. Biol. 42:420-433.

Marzluf, G. A. 1997. Genetic regulation of nitrogen metabolism in the fungi. Microbiol. Mol. Biol. Rev. 61:17-32.

McCormick, S. P., Harris, L. J., Alexander, N. J., Ouellet, T., Saparno, A., Allard, S., and Desjardins, A. E. 2004. Tri1 in Fusarium graminearum encodes a P450 oxygenase. Appl. Environ. Microbiol. 70:2044-2051.

McDonagh, A., Fedorova, N. D., Crabtree, J., Yu, Y., Kim, S., Chen, D., Loss, O., Cairns, T., Goldman, G., Armstrong-James, D., Haynes, K., Haas, H., Schrettl, M., May, G., Nierman, W. C., and Bignell, E. 2008. 
Sub-telomere directed gene expression during initiation of invasive Aspergillosis. PLoS Pathol. 4:e1000154.

Meek, I. B., Peplow, A. W., Ake, C., Jr., Phillips, T. D., and Beremand, M. N. 2003. Tril encodes the cytochrome P450 monooxygenase for C-8 hydroxylation during trichothecene biosynthesis in Fusarium sporotrichioides and resides upstream of another new Tri gene. Appl. Environ. Microbiol. 69:1607-1613

Mirocha, C. J., Kolaczkowski, E., Xie, W., Yu, H., and Jelen, H. 1998 Analysis of deoxynivalenol and its derivatives (batch and single kernel) using gas chromatography/mass spectrometry. J. Agric. Food Chem. 46:1414-1418.

Mudge, A. M., Dill-Macky, R., Dong, Y., Gardiner, D. M., White, R. G., and Manners, J. M. 2006. A role for the mycotoxin deoxynivalenol in stem colonisation during crown rot disease of wheat caused by Fusarium graminearum and Fusarium pseudograminearum. Physiol. Mol. Plant Pathol. 69:73-85.

Peplow, A. W., Tag, A. G., Garifullina, G. F., and Beremand, M. N. 2003. Identification of new genes positively regulated by Tri10 and a regulatory network for trichothecene mycotoxin production. Appl. Environ. Microbiol. 69:2731-2736.

Prieto, R., and Woloshuk, C. P. 1997. ord1, an oxidoreductase gene responsible for conversion of O-methylsterigmatocystin to aflatoxin in Aspergillus flavus. Appl. Environ. Microbiol. 63:1661-1666.

Proctor, R. H., Hohn, T. M., and McCormick, S. P. 1995a. Reduced virulence of Gibberella zeae caused by disruption of a trichothecene toxin biosynthetic gene. Mol. Plant-Microbe Interact. 8:593-601.

Proctor, R. H., Hohn, T. M., McCormick, S. P., and Desjardins, A. E. 1995b. Tri6 encodes an unusual zinc-ginger protein involved in regulation of trichothecene biosynthesis in Fusarium sporotrichioides. Appl. Environ. Microbiol. 61:1923-1930.

Proctor, R. H., Hohn, T. M., and McCormick, S. P. 1997. Restoration of wild-type virulence to Tri5 disruption mutants of Gibberella zeae via gene reversion and mutant complementation. Microbiology 143:25832591.

Ruepp, A., Zollner, A., Maier, D., Albermann, K., Hani, J., Mokrejs, M. Tetko, I., Güldener, U., Mannhaupt, G., Munsterkotter, M., and Mewes, H. W. 2004. The FunCat, a functional annotation scheme for systematic classification of proteins from whole genomes. Nucleic Acids Res. 32:5539-5545.

Rynkiewicz, M. J., Cane, D. E., and Christianson, D. W. 2001. Structure of trichodiene synthase from Fusarium sporotrichioides provides mechanistic inferences on the terpene cyclization cascade. Proc. Natl. Acad. Sci. U.S.A. 98:13543-13548.

Seong, K.-Y., Zhao, X., Xu, J.-R., Guldener, U., and Kistler, H. C. 2008 Conidial germination in the filamentous fungus Fusarium graminearum. Fungal Genet. Biol. 45:389-399.

Seong, K.-Y., Pasquali, M., Zhou, X., Song, J., Hilburn, K., McCormick, S., Dong, Y., Xu, J.-R., and Kistler, H.C. 2009. Global gene regulation by Fusarium transcription factors Tri6 and Tri10 reveals adaptations for toxin biosynthesis. Mol. Microbiol. 72:354-367.

Stephens, A. E., Gardiner, D. M., White, R. G., Munn, A. L., and Manners, J. M. 2008. Phases of infection and gene expression of Fusarium graminearum during crown rot disease of wheat. Mol. Plant-Microbe Interact. 21:1571-1581.

Tag, A. G., Garifullina, G. F., Peplow, A. W., Ake, C., Phillips, T. D., Hohn, T. M., and Beremand, M. N. 2001. A novel regulatory gene, Tri10, controls trichothecene toxin production and gene expression. Appl. Environ. Microbiol. 67:5294-5302.

Tobiasen, C., Aahman, J., Ravnholt, K. S., Bjerrum, M. J., Grell, M. N., and Giese, H. 2007. Nonribosomal peptide synthetase (NPS) genes in Fusarium graminearum, F. culmorum and F. pseudograminearium and identification of NPS2 as the producer of ferricrocin. Curr. Genet. 51:43-58.

Ward, T. J., Clear, R. M., Rooney, A. P., O’Donnell, K., Gaba, D., Patrick, S., Starkey, D. E., Gilbert, J., Geiser, D. M., and Nowicki, T. W. 2008. An adaptive evolutionary shift in Fusarium head blight pathogen populations is driving the rapid spread of more toxigenic Fusarium graminearum in North America. Fungal Genet. Biol. 45:473-484.

Woloshuk, C. P., Foutz, K. R., Brewer, J. F., Bhatnagar, D., Cleveland, T. E., and Payne, G. A. 1994. Molecular characterization of aflR, a regulatory locus for aflatoxin biosynthesis. Appl. Environ. Microbiol. 60:2408-2414.

\section{AUTHOR-RECOMMENDED INTERNET RESOURCES}

The MIPS Fusarium graminearum Genome Database: mips.gsf.de/genre/proj/FGDB

OmniMapFree homepage: www.omnimapfree.org/

PLEXdb Plant Expression database: www.plexdb.org 